\title{
Effect of particle size distribution on thermo-mechanical properties of NiO filled LDPE composites
}

\author{
D TRIPATHI ${ }^{1, *}$ and T K DEY ${ }^{2}$ \\ ${ }^{1}$ Department of Physics and Material Science and Engineering, Jaypee Institute of Information Technology, \\ Noida 201309, India \\ ${ }^{2}$ Cryogenic Engineering Centre, Indian Institute of Technology, Kharagpur 721302, India \\ *Author for correspondence (dineshazm83@gmail.com)
}

MS received 28 August 2018; accepted 20 January 2019; published online 30 May 2019

\begin{abstract}
The effect of nickel oxide (micro) addition on thermo-physical and mechanical properties of low density polyethylene (LDPE) has been studied. The samples have been prepared by the melt mixing process. The X-ray diffraction (XRD) and scanning electron microscopy (SEM) of the samples have been performed for micro-structural characterization and surface morphology, respectively. The XRD result confirms that the crystallinity of LDPE is affected by NiO addition, whereas the agglomeration of nickel oxide can be seen in the SEM photographs of LDPE samples having higher NiO loading. The thermal stability of the samples has been checked from DSC and TGA analyses under nitrogen atmosphere. The thermal stability of LDPE improves with the addition of a small amount of $\mathrm{NiO}$ particles. However, the peak melting temperature of LDPE/NiO composites decreases due to the dispersion of nickel oxide in the LDPE matrix. Again, the thermal conductivity of LDPE/NiO composites measured by a $\mathrm{KD}_{2}$ prothermal analyser increases approximately two times for $40 \mathrm{wt} . \%$ of $\mathrm{NiO}$ loaded LDPE composites. This increase in the thermal conductivity of LDPE may be explained on the basis of a model based on particle size distribution. The coefficient of linear thermal expansion (CTE) of the samples has been measured by a thermo-mechanical analyser as a function of temperature. The experimental value of CTE is well explained by taking the inter-phase volume and interaction between the filler particles and matrix into account. The mechanical properties of LDPE/NiO composites show an improvement with $\mathrm{NiO}$ addition and are explained in the light of various models and correlations.
\end{abstract}

Keywords. LDPE/NiO composites; thermal properties; coefficient of thermal expansion; mechanical properties.

\section{Introduction}

In recent years, polymer composites have drawn considerable interest due to their high strength to weight ratio, ease of processing, chemical inertness, good insulating properties and low cost. The low dielectric constant and minimal circuit signal delay make the polymer one of the most popular materials for electronic packaging. However, low thermal conductivity and large coefficient of linear thermal expansion (CTE) are certain disadvantages that restrict the use of polymers as electronic packaging materials. The miniaturization of electronic circuits and devices leads to self-heating during their use at high power and high frequency. This heat must be dissipated quickly and efficiently to prevent the devices from fatal damage [1]. Hence, to make polymers fit as electronic packaging materials, their thermal conductivity, coefficient of thermal expansion, thermal stability, mechanical strength, etc. must be tailored.

The improvement in thermal and mechanical properties of polymer composites depends on certain factors viz. type of fillers, filler size, filler geometry, inter particle contact and filler distribution in the matrix [2]. The addition of appropriate fillers in the polymer matrix solves not only the thermal dissipation problem, but also the thermal mismatch and mechanical properties related problems. Amongst the various types of fillers, metallic [3-5], carbon nano-tubes [6] and graphene $[7,8]$ are better candidates to improve the thermal conductivity of polymers. However, due to its high electrical conductivity, the polymer matrix filled with these fillers is not suitable for electronic packaging materials. Under such conditions, ceramic particle-based fillers are quite attractive since they can provide the required thermal conductivity without deteriorating their electrical insulation properties $[9,10]$. In this connection, $\mathrm{Lu}$ and $\mathrm{Xu}$ [11] reported that alumina $\left(\mathrm{Al}_{2} \mathrm{O}_{3}\right)$ dispersed in the polyurethane matrix increases its thermal conductivity by five times. Agrawal et al [12] used $\mathrm{SiO}_{2}$ as the filler for the styrene butadiene rubber matrix and observed a decrease in the thermal conductivity up to 10 vol.\% of $\mathrm{SiO}_{2}$ addition. However, at higher loading of $\mathrm{SiO}_{2}\left(\sim 40\right.$ vol. $\left.\% \mathrm{SiO}_{2}\right)$, the thermal conductivity increases from 0.143 to $0.182 \mathrm{~W} \mathrm{~m}^{-1} \mathrm{~K}^{-1}$. The discouraging result in thermal conductivity may be attributed to the porosity, poor wet out of filler or presence of moisture in bonding [12]. Weidenfeller et al [13] dispersed $\mathrm{Fe}_{3} \mathrm{O}_{4}$ in polypropylene (PP) and polyamide (PA) and found that thermal conductivity of $\mathrm{PP}$ and PA becomes 0.65 and $0.93 \mathrm{~W} \mathrm{~m}^{-1} \mathrm{~K}^{-1}$, respectively, for 44 
and 47 vol.\% of $\mathrm{Fe}_{3} \mathrm{O}_{4}$ addition. El-Brolossy and Ibrahim [14] used $\mathrm{ZnO}$ and $\mathrm{MnO}$ as fillers in the polystyrene matrix and reported an increase in the thermal conductivity with filler concentration in both the cases. Bujard et al [15] studied alumina-loaded epoxy composites for the moulding compound, and their thermal conductivity was compared with that of silica composites. Not only metal oxides and metal powders, but also metal nitrides and carbides play an important role as fillers to improve the thermal conductivity of polymer composites due to their high thermal conductivity, low dielectric constant and low cost. Yunsheng et al [9] reported thermal and dielectric properties of the PVDF/AIN system. In this connection, the thermal conductivities of polystyrene/AIN composites by $\mathrm{Yu}$ et al [16] and of HDPE/BN (micro and nano) composites by Jinwoo et al [10] have been reported. Their results show effective improvement in the thermal conductivity of polymers. The mechanical, thermo-mechanical and reprocessing behaviour of the biodegraded polymer and wood flour has been studied by Morreale et al [17]. Their results indicate an improvement in rigidity and creep resistance.

Again, due to low cost and frequency-independent dielectric and excellent mechanical properties, low-density polyethylene (LDPE) is a widely used polymer. A thermo-gravimetric study of $\mathrm{MgO}$ (nano) addition in LDPE indicates that the presence of moisture influences the dc conduction and space charge distribution in MgO/LDPE polymer composites [18]. Song et al [19] examined the structural, thermal, magnetic and dielectric properties of LDPE filled with multiferroic bismuth ferrite $\left(\mathrm{BiFeO}_{3}\right)$. In spite of shifting the diamagnetic nature of LDPE into anti-ferromagnetic, they observed an increase in dielectric permittivity and loss due to $\mathrm{BiFeO}_{3}$ addition. Recently, Marzouk et al [20] loaded agricultural waste, date pits in LDPE and found an enhancement in the thermomechanical properties of LDPE.

In summary, the addition of ceramic fillers in the polymer is found to be promising for polymer composite-based electronic packaging materials due to the fact that they can provide the required thermal conductivity without deteriorating their electrical insulation properties. Additionally, due to their low CTE and good mechanical properties, they can also solve the problem of thermal mismatch and poor mechanical properties of the polymer matrix by improving them. However, to date, good ceramic fillers that can fulfil the entire requirement are still under investigation. In view of the above, the present report has been undertaken to investigate the effect of $\mathrm{NiO}$ (micro) particle addition on thermal conductivity, CTE and mechanical properties of the LDPE matrix. The experimental results have been further analysed and discussed in light of various theoretical models and correlations.

\section{Experimental}

The samples of LDPE/NiO composites containing 0,10 , 20, 30 and 40 vol.\% of $\mathrm{NiO}$ (micro) particles have been prepared by the melt mixing process. For this, the commercial grade LDPE powder (density of $0.92 \mathrm{~g} \mathrm{cc}^{-1}$ ) and $\mathrm{NiO}$ powder (purity: $99.9 \%$, size: $~ 5-10 \mu \mathrm{m}$ and density: $6.67 \mathrm{~g} \mathrm{cc}^{-1}$ ) have been used as precursors. The appropriate amount of $\mathrm{NiO}$ powder is first mixed with LDPE powder with the help of an agate motor for $\sim 30 \mathrm{~min}$. The mixture is then added slowly to a sufficient amount of xylene and heated at $\sim 80^{\circ} \mathrm{C}$. The heating of the viscous fluid mixture with vigorous stirring continues for about $2 \mathrm{~h}$ until the solution becomes solidified. Here, it is important to mention that the vigorous stirring ensures the homogeneous distribution of $\mathrm{NiO}$ particles in the LDPE matrix. After solidifying, the mixture is kept on slow heat for 5-6 h to evaporate xylene completely. The mixture is then placed into a stainless steel die (dia. $\varphi=25 \mathrm{~mm}$ ) for moulding under a pressure of 3 tonne $\mathrm{cm}^{-2}$ at $120^{\circ} \mathrm{C}$. The samples for thermal conductivity and CTE measurement are moulded in the form of a cylinder (length: $35 \mathrm{~mm}$, dia.: $25 \mathrm{~mm}$ ), whereas for mechanical property measurement, rectangular sheets $(90 \times 65 \times 3 \mathrm{~mm})$ are moulded in a temperature controlled hot press under a pressure of 3.5 tonne $\mathrm{cm}^{-2}$.

The microstructural characterization of LDPE/NiO composites has been carried out by an XPERT-PRO diffractometer (range: $10-90^{\circ}$; step size: 0.02$)$ using a $\mathrm{CuK} \alpha(\lambda=1.5406 \AA)$ target. The surface morphology of the investigated samples is determined by a scanning electron microscope (SEM, model: PHILIPS XL-30/ESEM) operated with a beam voltage of $20 \mathrm{kV}$. The melting point of LDPE/NiO composites has been estimated by a Perkin Elmer Pyris Diamond differential scanning calorimeter (DSC) with a heating rate of $10^{\circ} \mathrm{C} \mathrm{min}{ }^{-1}$ in $\mathrm{N}_{2}$ atmosphere. Thermogravimetric analysis (TGA) has been performed to analyse the thermal stability of the sample by monitoring the $\%$ change in weight of the sample with temperature by using a Perkin Elmer DTA/TGA analyser.

The thermal conductivity of LDPE/NiO composites has been measured by a $\mathrm{KD}_{2}$ Pro analyser (model $\mathrm{KD}_{2}$ Pro, Decagon device Inc.) with an accuracy of $\pm 5 \%$. This analyser is based on the transient hot wire technique and is able to measure thermal conductivity, diffusivity and volumetric specific heat simultaneously in a short measurement time. Details about this method have been discussed elsewhere [2]. The CTE measurement of the investigated samples is performed by a Perkin Elmer Diamond thermo mechanical analyser. The specimen (dimension $\sim 5 \times 5 \times 5 \mathrm{~mm}$ ) is heated between 30 and $80^{\circ} \mathrm{C}$ with a heating rate of $5^{\circ} \mathrm{C} \mathrm{min}^{-1}$ and the slope of the thermal expansion $v s$. temperature curve is monitored to estimate the CTE as a function of temperature. The tensile test of the samples is carried out at room temperature by the universal testing machine (UTM) using dog bone-shaped samples (gauge length: $20 \mathrm{~mm}$ ).

\section{Results and discussion}

X-ray diffraction (XRD) patterns of pure and NiO-added LDPE polymer composites are shown in figure 1 . The peak 
matching of XRD patterns has been performed by X-pert High score plus software. The diffraction pattern of pure LDPE shows a single high intensity reflection at $2 \theta=21.35^{\circ}$. However, the intensity of this peak is found to be decreased

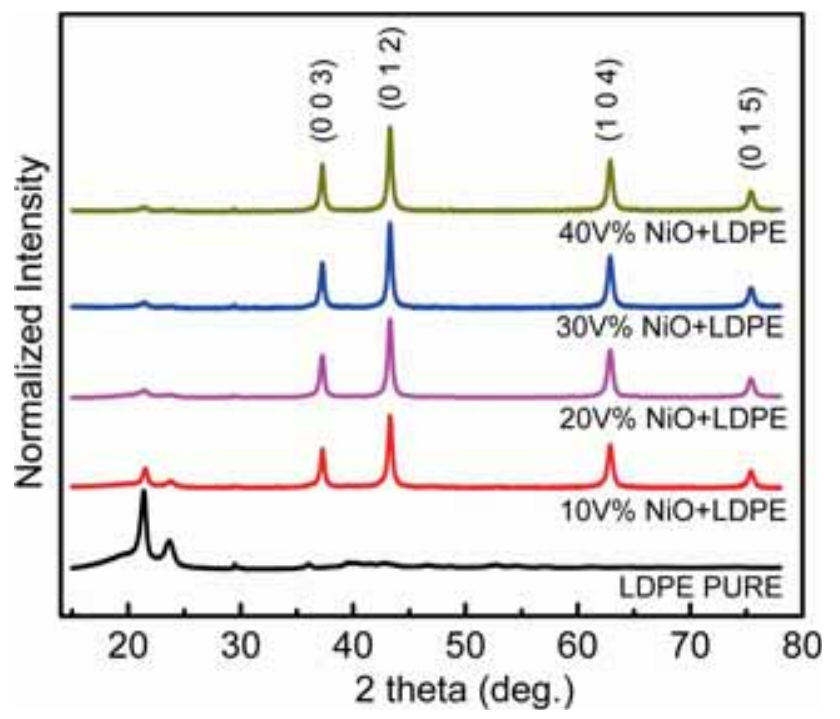

Figure 1. XRD pattern of $\mathrm{LDPE} / \mathrm{NiO}$ composites. for $\mathrm{NiO}$-added samples, which shows that the $\mathrm{NiO}$ addition decreases the crystallinity of the LDPE polymer. Except this, all the other peaks observed in $\mathrm{NiO}$-added samples correspond to the only $\mathrm{NiO}$ phase. This confirms the absence of any chemical reaction between LDPE and NiO during composite preparation.

Figure 2 represents some typical SEM photographs of pure and NiO-loaded LDPE composites. The photographs show a homogeneous distribution of $\mathrm{NiO}$ particles. However, for samples having higher $\mathrm{NiO}$ concentration ( $>20 \mathrm{vol} . \%$ ), a variation in the filler size may be noticed due to the agglomeration of $\mathrm{NiO}$ particles.

The SEM morphology of the fracture surface of nickel oxide-filled LDPE composites after the tensile test is shown in figure 3. It can be seen that the surface morphology of pure LDPE is relatively flat due to the uniform distribution of stress throughout the cross-sectional area. This results in a reduced stress concentration by absorbing the fracture energy and hence the occurrence of slip deformation. Again, the SEM photographs of the fractured surface of NiOadded LDPE depict the appearance of filamentous fibres and microcracks which increase with an increase in $\mathrm{NiO}$ concentration in LDPE. The appearance of filamentous fibres and microcracks initiates the roughness of the fractured surface
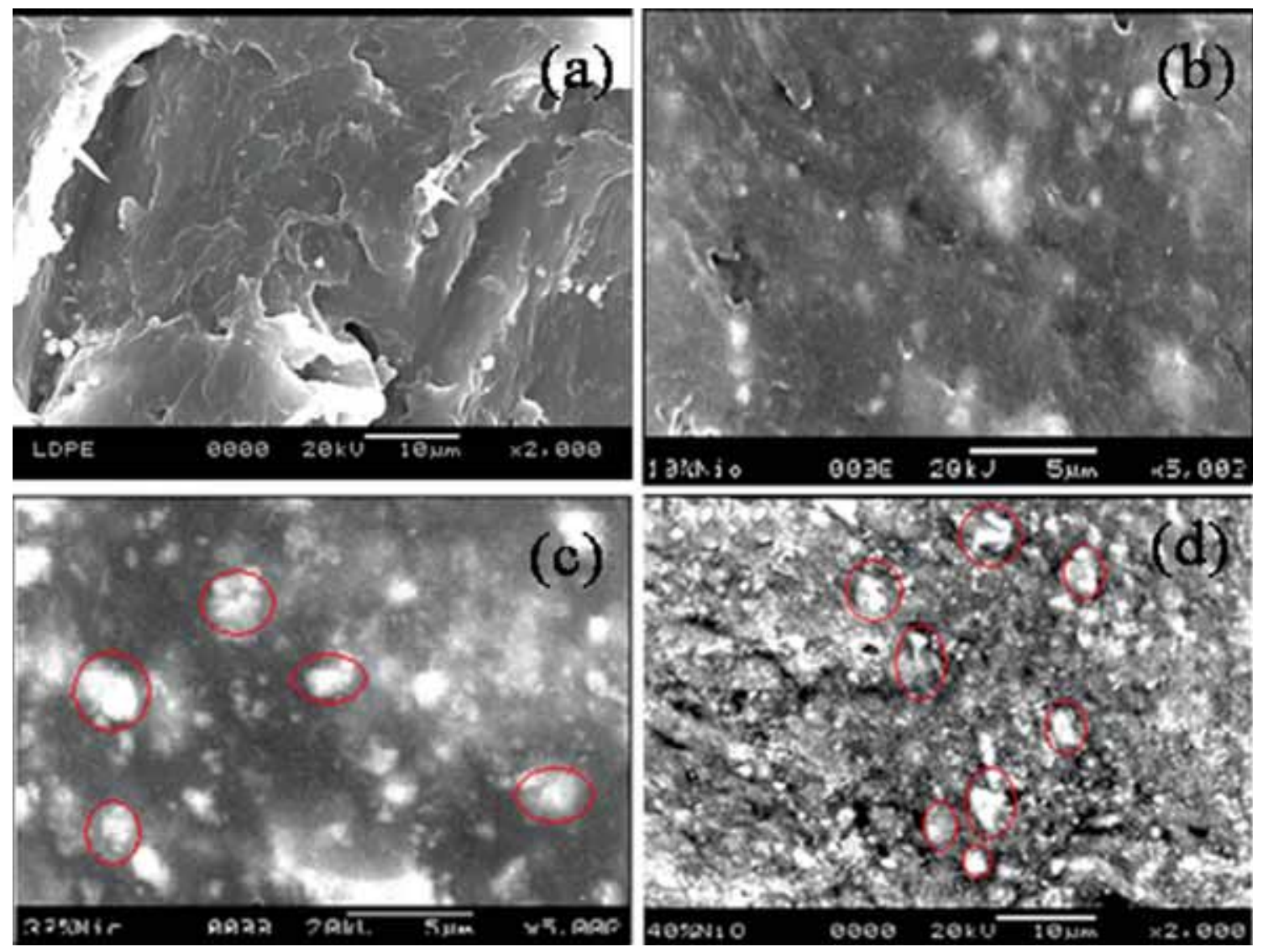

Figure 2. Typical SEM images of LDPE/NiO composites. 

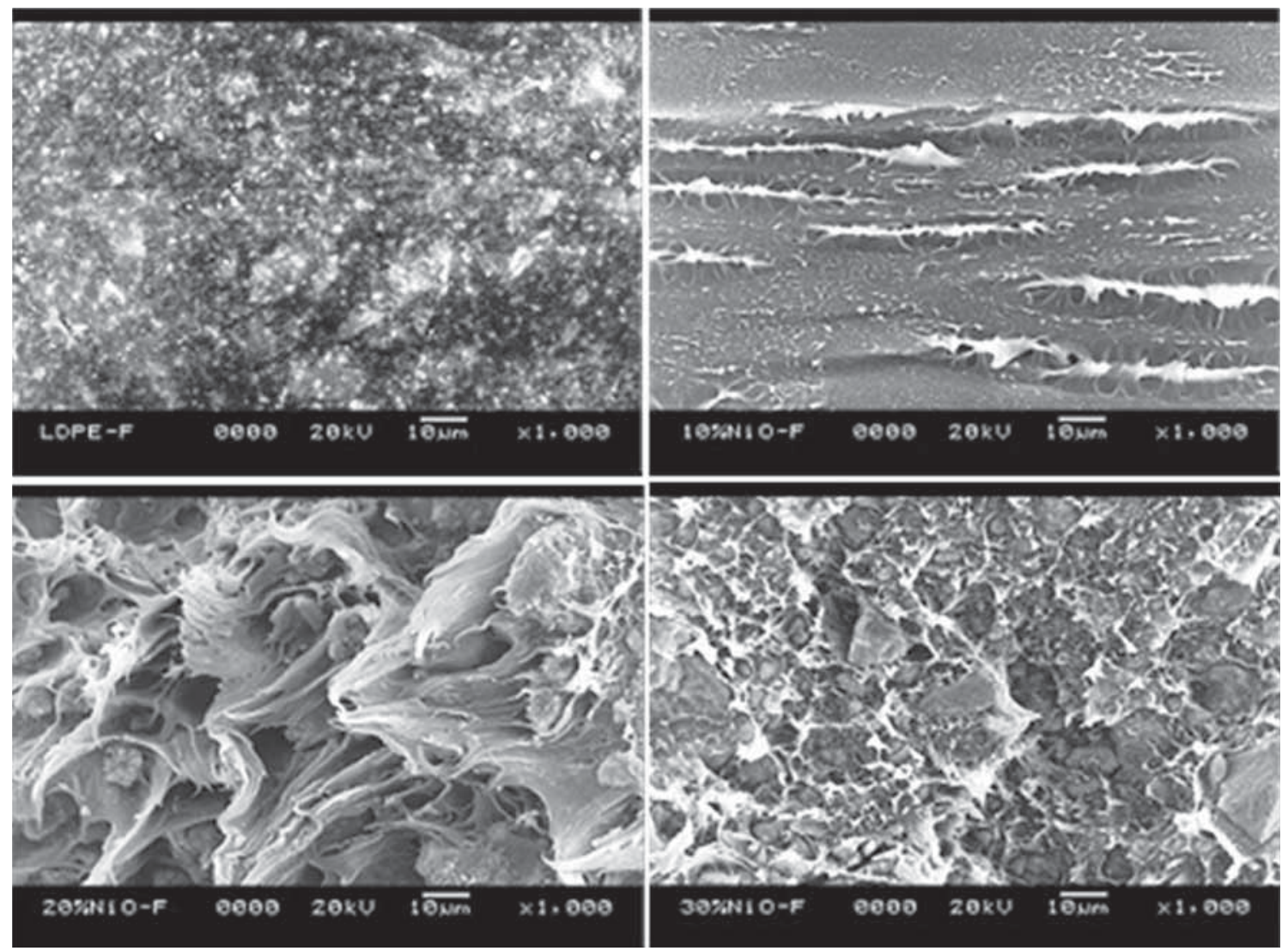

Figure 3. SEM micrograph of the fractured surface of LDPE/NiO composites.
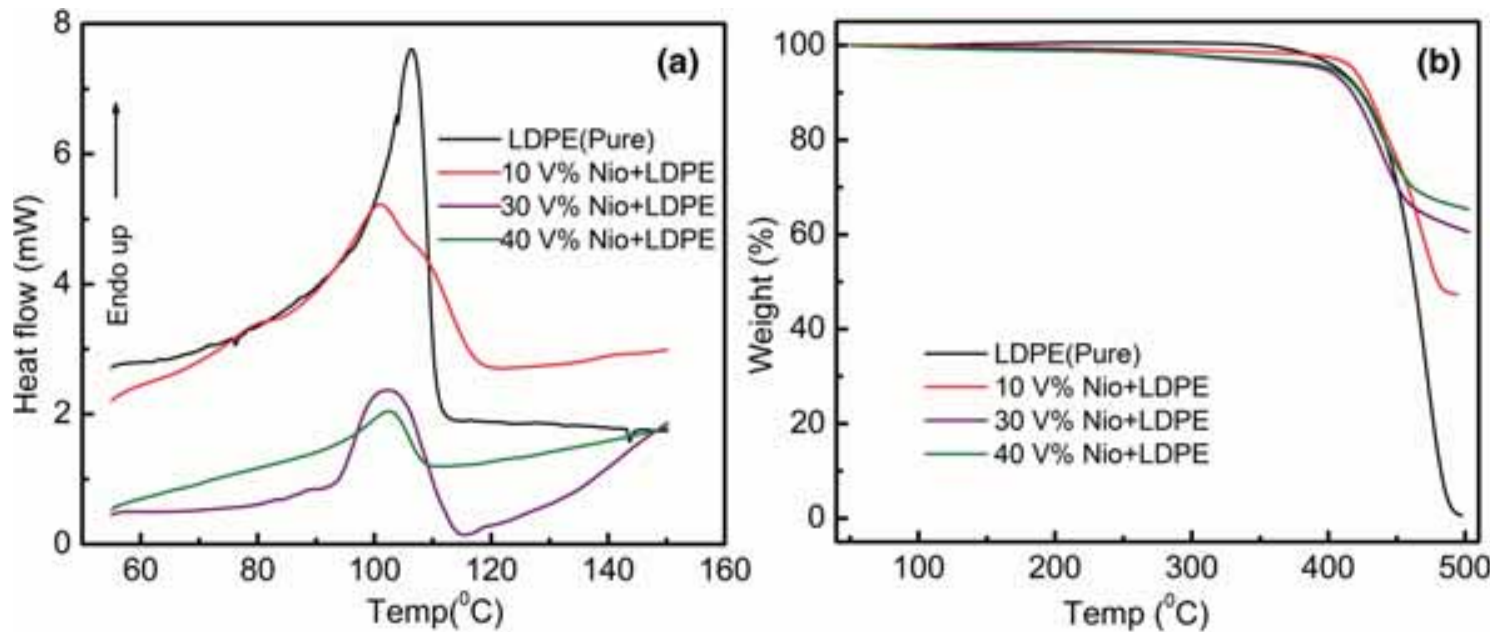

Figure 4. DSC and TGA curves of LDPE/NiO composites.

due to stress concentration around the filler particles and hence, leads to a decrease in fracture toughness.

The melting points and thermal stability of LDPE/NiO composites have been monitored through DSC and TGA, respectively. The DSC thermographs of LDPE/NiO composites are shown in figure $4 \mathrm{a}$. The melting temperature determined from the DSC thermographs is listed in table 1 for both pure and NiO-added LDPE. A marginal decrease in the peak melting temperature is observed due to the dispersion of $\mathrm{NiO}$, which confirms the influence of $\mathrm{NiO}$ particles on LDPE crystallinity [4]. Figure $4 \mathrm{~b}$ represents $\%$ variation in the mass of pure and NiO-added LDPE as a function of temperature 
Table 1. Peak melting points and temperatures at which samples lose $5\left(T_{5}\right), 10\left(T_{10}\right)$ and $15 \%\left(T_{15}\right)$ of their original weights.

\begin{tabular}{lcccc}
\hline & $\begin{array}{c}\text { Peak melting point } \\
\text { Composites }\end{array}$ & & & \\
\hline LDPE pure & $T_{\mathrm{p}, \mathrm{m}}\left({ }^{\circ} \mathrm{C}\right)$ & $T_{5}$ & $T_{10}$ & $T_{15}$ \\
LDPE + 10 vol.\% NiO & 106.3 & 404 & 423 & 433 \\
LDPE + 20 vol.\% NiO & 101.09 & 418 & 429 & 437 \\
LDPE + 30 vol.\% NiO & 101.87 & 398 & 419 & 428 \\
LDPE + 40 vol.\% NiO & 102.52 & 396 & 417 & 427 \\
& 101.36 & 402 & 423 & 432 \\
\hline
\end{tabular}

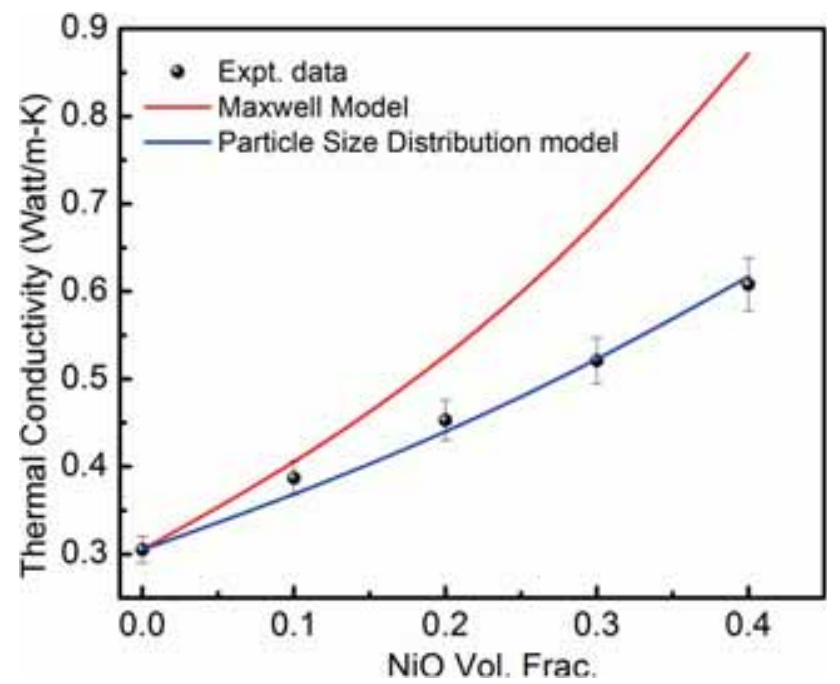

Figure 5. The room temperature thermal conductivity of LDPE/NiO cmposites fitted with the Maxwell and particle size distribution model as a function of $\mathrm{NiO}$ volume fraction.

(TGA graph). The temperature at which the sample loses 5, 10 and $15 \%$ of its weight has been monitored and is listed in table 1 as $T_{5}, T_{10}$ and $T_{15}$, respectively. As is clear from table 1 , the thermal stability of LDPE increases for a low level of $\mathrm{NiO}$ addition (up to $10 \mathrm{vol} \%$ ). However, a small decrease in the thermal stability of LDPE/NiO composites can be seen for high $\mathrm{NiO}$ concentration. This may happen because of the clustering of $\mathrm{NiO}$, which may cause an increase in energy propagation [4].

The thermal transport behaviour (i.e., thermal conductivity) of the pure and $\mathrm{NiO}$-added LDPE composites has been studied as a function of filler $(\mathrm{NiO})$ concentration at room temperature. The thermal conductivity of LDPE $\left(0.305 \mathrm{~W} \mathrm{~m}^{-1} \mathrm{~K}^{-1}\right)$ is found to increase with $\mathrm{NiO}$ concentration and reaches a value of $0.608 \mathrm{~W} \mathrm{~m}^{-1} \mathrm{~K}^{-1}$ ( $\sim 2$ times) for $40 \mathrm{vol} \% \mathrm{NiO}$ added pellets as shown in figure 5 . The increase in the thermal conductivity may be explained on the basis of the heat conduction mechanism through lattice vibration. Since the propagating rate of thermal flow depends on the coupling between the lattice vibrations of one atom with their adjacent atoms, an increase in filler content increases the interaction between the particles and hence, forms a thermal path [2].
The experimental value of thermal conductivity of LDPE/ $\mathrm{NiO}$ composites has been analysed in light of various theoretical models and empirical correlations applicable for two component composites [21-28]. These models are based on various parameters viz. filler size and shape, filler loading, homogeneity of dispersed phase in the matrix, etc. The applicability of these models for the two component system has been discussed elaborately in different reports [29-31]. However, it has been noticed that most of the models fail to explain the thermal conductivity variation of $\mathrm{LDPE} / \mathrm{NiO}$ composites.

The thermal conductivity of the LDPE/NiO system is well explained by the effective particle size distribution model proposed by Holotescu et al [28]. They observe that at lower concentration, when there is no interaction between the filler particles, all the randomly distributed particles are of similar size, but the situation is quite different at higher concentration where the potential around each filler is influenced by the potential of others due to agglomeration and hence, most of the analytical models fail to explain the experimentally observed thermal conductivity of polymer composites at higher filler concentration. To overcome this situation, Holotescu et al [23] extended the analytical models by including the effect of the filler particle size distribution law in their equations. For this, they replaced the real system having uniformly distributed filler particles of different sizes with an identical system made of same constituents in which equal size filler particles having equivalent volume fraction $\left(\varphi_{\mathrm{e}}\right)$ are uniformly distributed. The volume fraction $\left(\varphi_{\mathrm{e}}\right)$ can be approximated by using the Rosin-Rammler distribution and is expressed as:

$$
\varphi_{\mathrm{e}}=\frac{\Gamma^{2}(1+3 / s)}{\Gamma^{3}(1+2 / s)} \varphi=\chi \varphi,
$$

where $s$ is the shape parameter that defines the filler particle size distribution law. The higher the value of the shape parameter, the smaller is the deviation between equivalent volume fraction $\varphi_{\mathrm{e}}$ and actual volume fraction $\varphi$, and for $s=\infty, \varphi$ and $\varphi_{\mathrm{e}}$ become equal. Therefore, the effective thermal conductivity of the composite may be expressed as:

$$
K=K_{\mathrm{m}}\left[\frac{\left(2 K_{\mathrm{m}}+K_{\mathrm{f}}+2 \varphi_{\mathrm{e}}\left(K_{\mathrm{f}}-K_{\mathrm{m}}\right)\right)}{\left(2 K_{\mathrm{m}}+K_{\mathrm{m}}-\varphi_{\mathrm{e}}\left(K_{\mathrm{f}}-K_{\mathrm{m}}\right)\right)}\right] .
$$

A combined plot of measured thermal conductivity data along with those estimated with the help of the particle size distribution model is shown in figure 5. The figure infers a fair correspondence of the particle size distribution model with experimental thermal conductivity data for $\chi=0.6647$. Again, if we compare the thermal conductivity value of LDPE/NiO composites obtained from Maxwell and the particle size distribution model with the experimental result (figure 5), we observe that at low filler concentration $(\leq 10$ vol.\%), in the absence of agglomeration, Maxwell's model gives the better approximation of thermal conductivity data as compared to the particle size distribution model. On the other 

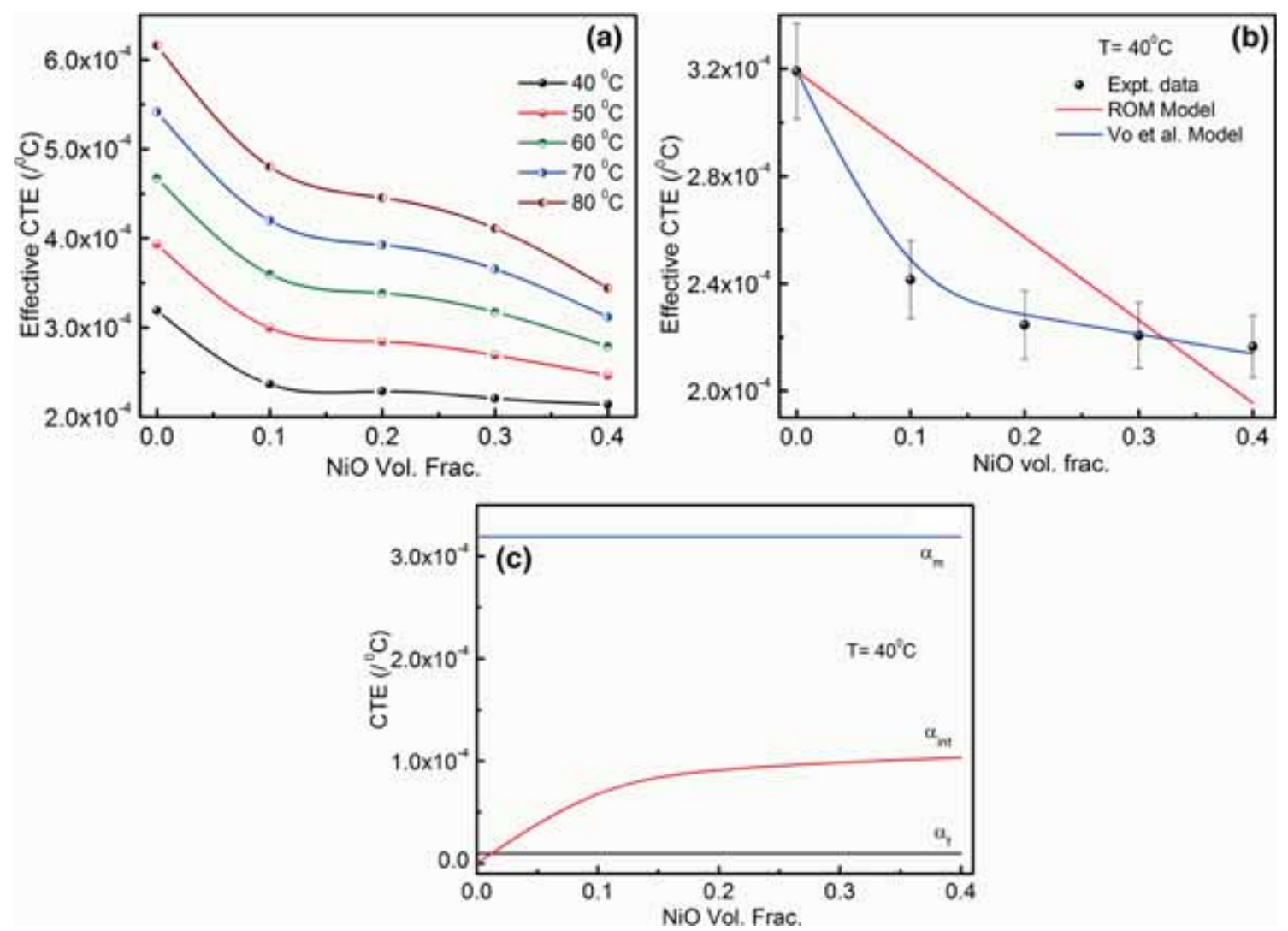

Figure 6. (a) Variation of the effective $\mathrm{CTE}$ as a function of $\mathrm{NiO}$ concentration at different temperatures for $\mathrm{LDPE} / \mathrm{NiO}$ composites, (b) validation of experimental results using relevant models and (c) variation of CTE of interface, $\mathrm{NiO}$ and $\mathrm{LDPE}$ as a function of $\mathrm{NiO}$ volume fraction.

hand, at higher filler concentration (i.e., $>10$ vol.\%), when agglomeration and the thermal barrier due to the interface surrounding the filler particles start dominating, the thermal conductivity is explained well by the particle size distribution model as the Maxwell model overestimates the experimental result.

The variation of the CTE of the LDPE/NiO composites as a function of $\mathrm{NiO}$ volume fraction is shown in figure $6 \mathrm{a}$ between 40 and $80^{\circ} \mathrm{C}$. The CTE of all the investigated samples is found to increase with an increase in temperature. On the other hand, the increase in the $\mathrm{NiO}$ volume fraction causes a significant decrease in the CTE of LDPE (figure 6a). This decrease in the CTE of NiO-reinforced LDPE is due to the substantially low CTE of $\mathrm{NiO}\left(\sim 1 \times 10^{-5}{ }^{\circ} \mathrm{C}^{-1}\right)$ as compared to pure LDPE $\left(\sim 3.2 \times 10^{-4}{ }^{\circ} \mathrm{C}^{-1}\right)$ at room temperature. Therefore, as we move towards the higher filler concentration, the CTE of the fillers starts playing a dominating role that causes an overall decrease in the CTE of the composite ( $33 \%$ for 40 vol.\% $\mathrm{NiO}$-added LDPE at $40^{\circ} \mathrm{C}$ ).

The effect of the filler concentration on the CTE of LDPE is further analysed in the vicinity of different existing theoretical and empirical models [32-36] at $40^{\circ} \mathrm{C}$. These models and correlations are based on several factors such as bulk modulus, shear modulus, Young's modulus, interface between filler particles, etc. of both the filler and matrix. The rule of mixing (ROM) model considers that the filler and matrix are expanding individually without hampering each other [32]. The Turner model [33] assumes a uniform distribution of strain in the matrix and filler with negligible shear deformation. Kerner [34] proposed the expression by considering isotropic and homogeneous distribution of spherical filler particles wetted by a uniform layer of matrix. However, Blackburn [35] included the Poisson ratio and elastic modulus of the constituent particles for predicting the effective CTE of the composite material. Here, it is important to mention that the value of effective CTE estimated from all the above models is far away from the experimental CTE data.

Vo et al [36] argued that the CTE estimated by the ROM model is always greater than the experimental value due to the face that the ROM model does not include the interface interaction, while the CTE estimated by the Turner model is close to the CTE of the filler as the bulk modulus of the filler is much larger than the matrix. Vo et al [36] accounted for the interfacial volume surrounding the filler particles and proposed an analytical model to explain the CTE of polymer composites. According to them, the volume of the composite $\left(V_{\mathrm{c}}\right)$ is the sum of the respective volumes of the matrix $\left(V_{\mathrm{m}}\right)$, 

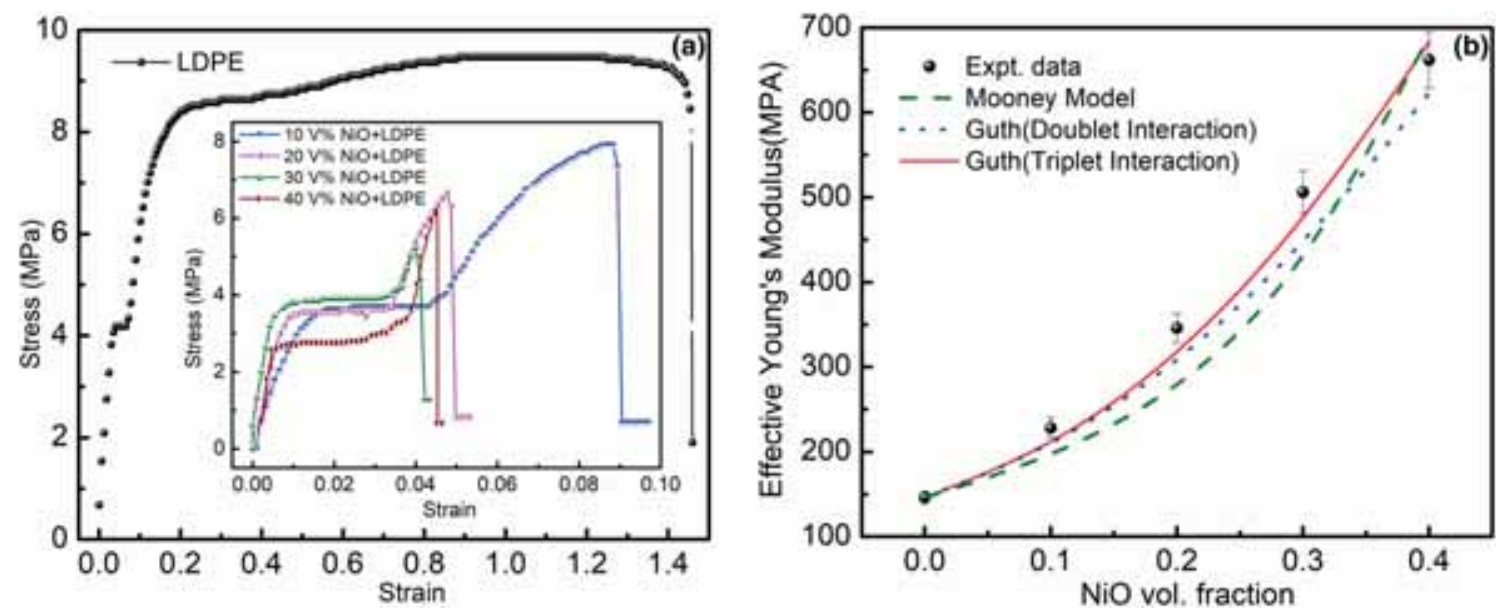

Figure 7. (a) Stress-strain curve and (b) comparison of the experimental value of Young's modulus of LDPE/NiO with those estimated by the Mooney and Guth models.

filler $\left(V_{\mathrm{f}}\right)$ and interface $V_{\text {int }}[36]$ i.e.,

$$
V_{\mathrm{c}}=V_{\mathrm{f}}+V_{\mathrm{m}}+V_{\text {int }} .
$$

Here, $V_{\text {int }}$ includes the volume of the interface between the matrix and filler and the filler-filler overlapping. Thus, the final expression for an effective CTE is given by:

$$
\begin{aligned}
\alpha= & \frac{1}{1+K_{0} \varphi_{\mathrm{f}} \varphi_{\mathrm{m}}}\left[\alpha_{\mathrm{f}} \varphi_{\mathrm{f}}+\alpha_{\mathrm{m}} \varphi_{\mathrm{m}}\right. \\
& \left.+K_{0} \varphi_{\mathrm{f}} \varphi_{\mathrm{m}}\left(\alpha_{\mathrm{f}}+\alpha_{\mathrm{m}}\right)+K_{0} \varphi_{\mathrm{f}} \varphi_{\mathrm{m}} K_{1}\right],
\end{aligned}
$$

where $\varphi_{\mathrm{m}}=\left[\left(1-\varphi_{\mathrm{f}}\right) /\left(1+K_{0} \varphi_{\mathrm{f}}\right)\right]$.

The terms $K_{0}$ and $K_{1}$ in the above expression are constants. The value of $K_{0}$ depends on the strength of the matrix filler interaction and varies with the filler shape, size and preparation conditions. On the other hand, $K_{1}$ shows the variation of $\ln K_{0}$ with respect to temperature and is related to $\alpha_{\text {int }}$ as given below:

$$
\alpha_{\text {int }}=K_{1}+\alpha_{\mathrm{f}}+\alpha_{\mathrm{m}}-\alpha_{\mathrm{c}} .
$$

Figure $6 \mathrm{~b}$ represents the experimental CTE data along with that estimated by Vo et al's [36] model. It may be noted that our experimental data are explained well by Vo et al's model in the whole range of filler concentration. The values of the fitting parameters $K_{0}$ and $K_{1}$ thus obtained are 8.90 and $-1.04 \times 10^{-5}$, respectively. The high $K_{0}$ value shows a strong interaction between the LDPE and $\mathrm{NiO}$ particles. However, the value of $K_{1}$ is further used to calculate the CTE of the interface by using equation (5). The variation of $\alpha_{\text {int }}$ with filler concentration along with the CTE of $\mathrm{NiO}\left(\alpha_{\mathrm{f}}\right)$ and LDPE $\left(\alpha_{\mathrm{m}}\right)$ is plotted in figure 6c. The figure infers an increase in the CTE of the interface with an increase in $\mathrm{NiO}$ concentration, which confirms that the interface plays a dominating role in determining the CTE of polymer composites. Here, it is important to mention that the negative value of $K_{1}$ predicts the effective CTE to be smaller than that predicted by the ROM model [36].

The addition of fillers in the polymer matrix leads to an increase in the elastic energy due to the perturbation of stresses and strains set up in the polymer composites [37]. To investigate the elastic properties of the LDPE/NiO composite as a function of filler concentration, the tensile test of all the investigated samples has been performed by the UTM at room temperature. A typical stress strain curve is plotted in figure 7a for different $\mathrm{NiO}$ concentrations. Young's modulus, which is defined as the ratio of stress to strain (stiffness) at the elastic edge has been estimated from the stress strain curve and is plotted as a function of $\mathrm{NiO}$ concentration (figure $7 \mathrm{~b}$ ). The figure reveals an increase in Young's modulus of LDPE with $\mathrm{NiO}$ addition and may be explained on the basis of the higher stiffness of the $\mathrm{NiO}$ particle [38].

Similar to thermal conductivity and the CTE, various empirical or semi-empirical expressions have been proposed to predict Young's modulus of polymer composites [37-43]. These models are based on different assumptions. Einstein [39] assumed the dilute suspension and perfect adhesion between the spherical filler and matrix to derive an expression for Young's modulus of polymer composites, while Kerner [40] considered isotropic and homogeneous distribution of spherical filler particles surrounded by a uniform layer of the matrix. Nielsen [41] modified the Halpin and Tsai model, and derived a semi-empirical expression containing the factors related to particle shape, orientation and type of packing. Counto [42] proposed a simple model for the polymer composite by assuming perfect bonding between the filler and matrix. Here, it is important to mention that most of the models discussed above are far behind the experimental result. Both Mooney [43] and Guth [37] further modified the Einstein model by considering the interaction between particles. Mooney [43] introduced a crowding factor term $(s)$, which is the ratio of apparent volume occupied by the 

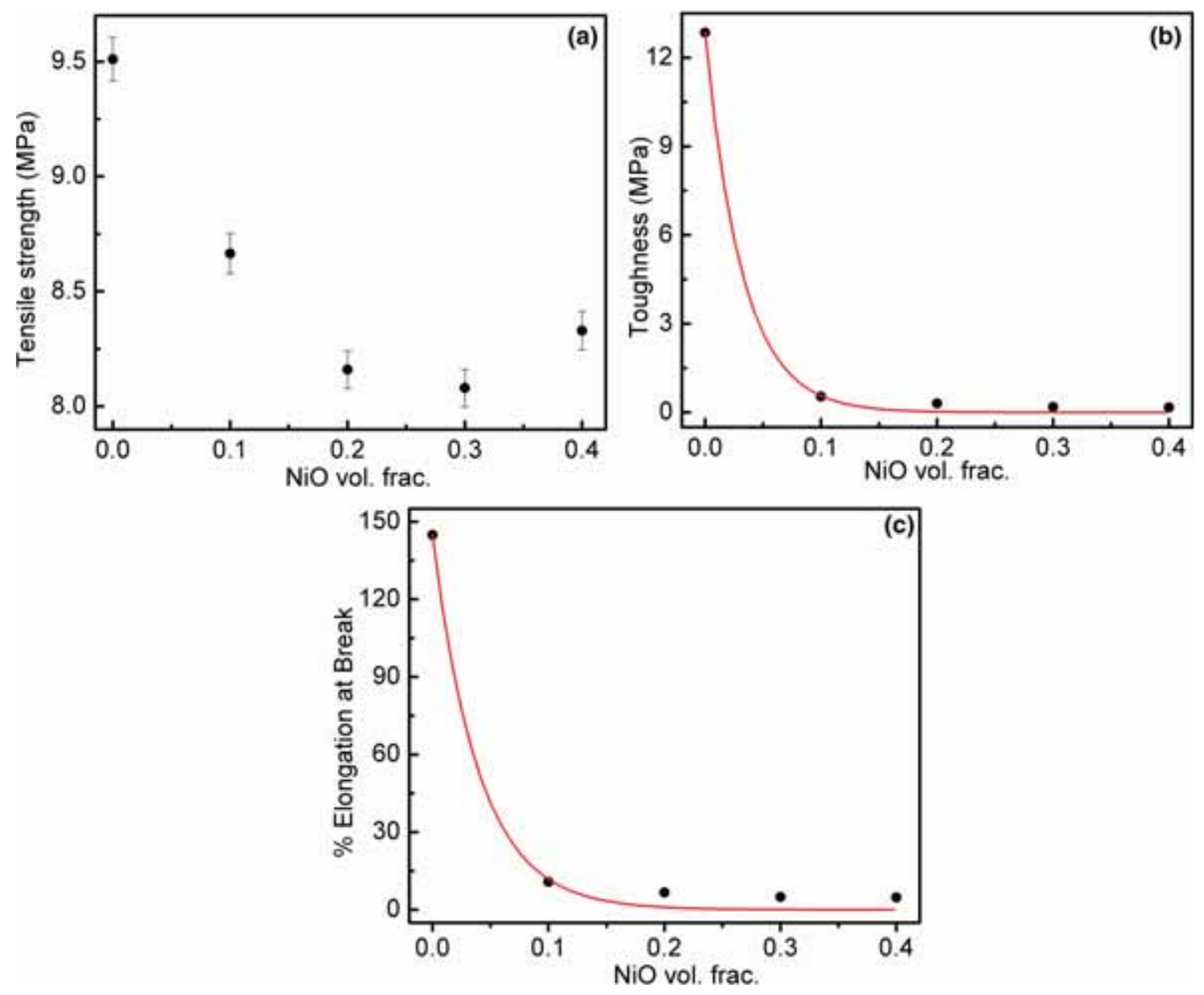

Figure 8. Variation of (a) tensile strength; (b) toughness and (c) percentage elongation at break of LDPE/NiO composites as a function of $\mathrm{NiO}$ concentration.

filler to its own true volume and derived expressions for both spherical and non-spherical filler particles. On the other hand, Guth modified Einstein's expression by assuming that at a higher concentration, the elastic Young's modulus of polymer composites is not a linear function of filler concentration $(\varphi)$, but can be expressed by a power series in $\varphi$ as below:

$$
E=E_{\mathrm{m}}\left(1+\alpha_{1} \varphi+\alpha_{2} \varphi^{2}+\alpha_{3} \varphi^{3}+\cdots\right),
$$

where the coefficients $\alpha_{1}, \alpha_{2}, \alpha_{3}$, etc. are numerical factors and depend on the shape and interaction between the filler particles viz., for spherical particles $\alpha_{1}=2.5$ and represent independent action of filler particles (up to 10 vol. $\%$ of filler concentration), while at higher concentration, $\alpha_{2}, \alpha_{3}$, $\alpha_{4}$, etc. represent the mutual interaction among pairs, triplets and quadruplets of filler particles, respectively. Guth and Gold [44] used the method of images in electrostatics to compute the interaction coefficient $\alpha_{2}$ when a pair of filler particles mutually interacts (doublet interaction) and, in the case of spherical shape particles, the computed value of $\alpha_{2}$ is found to be 14.1. Thus, considering the doublet interaction, Guth and Gold [44] proposed the following expression for Young's modulus:

$$
E=E_{\mathrm{m}}\left(1+2.5 \varphi+14.1 \varphi^{2}\right) .
$$

It may be noticed from figure $7 b$ that the value of Young's modulus calculated by using the above expression gives some better estimation of the experimental results as compared to the Mooney model. Furthermore, as the analysis of thermal conductivity and CTE data reveal the agglomeration of filler particles, we have included the term corresponding to triplet interaction in equation (7) as expressed below:

$$
E=E_{\mathrm{m}}\left(1+2.5 \varphi+14.1 \varphi^{2}+\alpha_{3} \varphi^{3}\right)
$$

The above expression, when fitted with experimental data, gives a fair correspondence for the $\alpha_{3}$ value equal to $\sim 6.5$ (figure $7 \mathrm{~b}$ ) and hence, validate the agglomeration of $\mathrm{NiO}$ particles in the LDPE matrix.

For tensile strength analysis of LDPE/NiO composites, the maximum stress borne by the samples during the tensile test 
has been estimated from the stress-strain curve. A plot of tensile strength is plotted in figure $8 \mathrm{a}$ as a function of $\mathrm{NiO}$ filler concentration. The curve shows a decrease in tensile strength at low filler concentration, but after that, it starts increasing. This is because at low filler loading, when samples are stretched, the stress concentration occurs around the filler particles. At higher loading, the nickel oxide particles get agglomerated and increase mutual interaction between filler particles. This gives rise to an increase in the tensile strength of polymer composites.

The ductility/brittleness of NiO-filled LDPE composites has been investigated by measuring the variation in toughness and percentage elongation at break of LDPE due to NiO addition. Here, it is important to mention that the toughness is the ability of a material to absorb energy to deform plastically and is measured by the area under the stress-strain curve. On the other hand, elongation at break is the ratio of the maximum increase in the length of the sample during the tensile test to its initial length. Figure $8 \mathrm{~b}$ and $\mathrm{c}$ represents the variation in toughness and \% elongation at break of LDPE/NiO composites as a function of $\mathrm{NiO}$ fraction, respectively. Both show a first order exponential decrease with an increase in $\mathrm{NiO}$ concentration, which indicates that the addition of nickel oxide decreases the ductility and increases the brittleness of LDPE [3].

\section{Conclusions}

Thermo-physical and mechanical properties of LDPE/NiO composites prepared by the melt mixing process are presented as a function of temperature and $\mathrm{NiO}$ volume concentration. The XRD pattern confirms a reduction in the crystallinity of LDPE by NiO addition. However, the different sized agglomerations can be seen in SEM micrographs of samples having high $\mathrm{NiO}$ concentration. On the other hand, the SEM photographs of the fractured surface reveal uniform distribution of stress throughout the whole cross-sectional area for pure LDPE, while the stress is concentrated around the $\mathrm{NiO}$ particles in NiO-added LDPE. The TGA analysis confirms an improvement in the thermal stability of LDPE due to $\mathrm{NiO}$ addition, whereas the dispersion of $\mathrm{NiO}$ particles in the LDPE matrix reduces the peak melting temperature of LDPE by $5^{\circ} \mathrm{C}$ as confirmed by the DSC thermograph. The room temperature thermal conductivity is found to be increased from 0.305 to $0.608 \mathrm{~W} \mathrm{~m}^{-1} \mathrm{~K}^{-1}$ ( $\sim 2$ times) for LDPE added with $40 \mathrm{wt} . \% \mathrm{NiO}$ and is well explained in the vicinity of a theoretical model based on the particle size distribution in the polymer matrix. The CTE of LDPE at $40^{\circ} \mathrm{C}\left(\sim 10^{-5}{ }^{\circ} \mathrm{C}^{-1}\right)$ decreases considerably with $\mathrm{NiO}$ addition $(\sim 33 \%$ for 40 vol. \% NiO-added LDPE composites), and is interpreted by considering the presence of inter-phase volume as well as the interaction between the filler particles and matrix. Again, more than four times improvement in Young's modulus of LDPE has been observed for $40 \mathrm{wt}$ \% $\mathrm{NiO}$ addition and is explained by assuming the doublet and triplet interactions between the filler particles. However, the toughness and ductility of LDPE show a first-order exponential decrease with $\mathrm{NiO}$ addition.

\section{References}

[1] Hong J, Yoon S, Hwang T, Oh J, Hong S, Lee Y et al 2012 Thermochim. Acta 53770

[2] Tripathi D and Dey T K 2013 Indian J. Phys. 87435

[3] Tavman I H 1997 Powder Technol. 9163

[4] Molefi J A, Luyt A S and Krupa I 2009 Express Polym. Lett. 3 639

[5] Mamunya Y P, Davydenko V V, Pissis P and Lebedev E V 2002 Eur. Polym. J. 381887

[6] Zhou Y X, Wu P X, Cheng Z Y, Ingram J and Jeelani S 2008 Express Polym. Lett. 240

[7] Qi X, Pu K Y, Li H, Zhou X, Wu S, Fan Q L et al 2010 Angew. Chem. Int. Ed. 499426

[8] Ramanathani T, Abdala A A, Stankovich S, Dikin D A, Herrera Alonso M et al 2008 Nat. Nanotechnol. 3327

[9] Yunsheng X, Chung D D L and Cathleen M 2001 Compos. A 321749

[10] Jinwoo J, Jaewoo K, Rang U Y, Jae-Kyun J, Sol L, Min L H et al 2010 Thermochim. Acta 4998

[11] Lu X and Xu G 1997 Appl. Polym. Sci. 652733

[12] Agrawal R, Saxena N S, Mathew G, Thomas S and Sharma K B 2000 J. Appl. Polym. Sci. 761799

[13] Weidenfeller B, Hofer M and Schilling F 2002 Compos. A 33 1041

[14] El-Brolossy T A and Ibrahim S S 2010 Thermochim. Acta 509 46

[15] Bujard P, Kuhnlein G, Ino S and Shiobara T 1994 IEEE Trans. Compon. Packag. Manuf. Technol. Part A 4527

[16] Yu S, Hing P and Hu X 2002 Compos. A 33289

[17] Morreale M, Liga A, Mistretta M C, Ascione L and Mantia F P L 2015 Materials 87536

[18] Yang J, Wang X, Zhao H and Zhang W 2014 IEEE Trans. Dielectr. Electr. Insul. 211957

[19] Song W, Sun Z, Zhang D, Han B, He L, Wang X et al 2016 J. Mater. Sci. Mater. Electron. 272328

[20] Marzouk W, Bettaieb F, Khiari R and Majdoub H 2017 J. Thermoplast. Compos. Mater. 301200

[21] Tavman I H 1998 Int. Commun. Heat Mass Transf. 25723

[22] Hamilton R L and Crosser O K 1962 Ind. Eng. Chem. Res. 1 187

[23] Maxwell J C 1954 3rd ed (New York: Dover) Ch. 9

[24] Lewis T and Nielsen L 1970 J. Appl. Polym. Sci. 141449

[25] Cheng S C and Vachon R I 1969 Int. J. Heat Mass Transf. 12 249

[26] Meredith R E and Tobias C W 1962 Advances in electrochemistry and electrochemical engineering (New York: Wiley Interscience Publishers) vol. 2, p 15

[27] Zhang G, Xia Y, Wang H, Tai Y, Tao G, Tu S et al 2009 J. Compos. Mater. 44963

[28] Holotescu S and Stoian F D 2009 J. Zhejiang. Univ. Sci. 10704

[29] Progelhof R C, Throne J H and Ruetsch R R 1976 Polym. Eng. Sci. 16615 
[30] Ott H J 1981 Plast. Rubber Process. Appl. 19

[31] Shen H, Cui Y, He J and Zhang Y 2011 Int. J. Miner. Metall. Mater. 18623

[32] Zhang Q, Wu G, Sun D and Luan B 2002 J. Mater. Sci. Technol. 1863

[33] Turner P S 1946 J. Res. Natl. Bureau. Stand. 37239

[34] Kerner H 1956 Proc. Phys. Soc. B 69802

[35] Blackburn W S 1961 Philos. Mag. 6503

[36] Vo H T, Todd M, Shi F G, Shapiro A A and Edwards M 2001 Microelectron. J. 32331
[37] Guth E 1945 J. Appl. Phys. 1620

[38] Fu S Y, Feng X Q, Lauke B and Mai Y W 2008 Compos. B 39 933

[39] Einstein A 1956 Investigations on the theory of the Brownian movement (New York: Dover Pub. Inc.)

[40] Kerner E H 1956 Proc. Phys. Soc. B 69808

[41] Nielsen L E 1970 J. Appl. Phys. 414626

[42] Counto U J 1964 Mag. Concr. Res. 16129

[43] Mooney M 1951 Colloid. Sci. 6162

[44] Guth E and Gold O 1938 Phys. Rev. 53322 